This document is the Accepted Manuscript version of a Published Work that appeared in final form in British Journal of Nursing, copyright @ MA Healthcare, after peer review and technical editing by the publisher. To access the final edited and published work see https://doi.org/10.12968/bjon.2019.28.15.964 


\title{
Intermittent self-catheterisation: good patient education and support are key
}

\author{
Linda Collins, Associate Professor in Adult Nursing, Kingston University and St George's University of London, \\ L.Collins@sgul.kingston.ac.uk
}

Urinary retention is the inability to passively void urine, and the preferred treatment method for managing this bladder condition is clean intermittent selfcatheterisation (CISC) (Blok et al, 2017).CISC may be initiated for many reasons, but it is most commonly performed when there is residual urine in the bladder that is accompanied with voiding symptoms or complications, such as urinary tract infections, discomfort, voiding symptoms and incontinence (Vahr et al, 2012; 2013a; 2013b). Bladder treatments such as botulinum toxin injections and oral antimuscarinics are prescribed to reduce detrusor overactivity, but can cause incomplete bladder emptying if overly effective (Liberman et al, 2018), and CISC is often initiated for this cause. CISC is achieved when the catheter is inserted into the urethral orifice, along the urethra and into the bladder to eliminate urine (Dougherty et al, 2015). Patients who have been diagnosed with long-term urinary retention are often taught to self-catheterise independently. Although CISC may be perceived as an arduous endeavour by patients, it is regarded as an intervention that will improve quality of life and facilitate independence for patients who have long-term urinary retention (Logan et al, 2008).

\section{Patient education for CISC}

Patients are frequently assessed on their capacity to process, obtain and understand healthcare-related information accompanied by clinical instruction. This is often referred to as 'health literacy' (Somers and Mahadevan, 2010).The level of health literacy a patient has acquired is crucial, and more so when evaluating a patient's understanding of health information and instructions to perform self-care at home (Yen and Leasure, 2019). According to Le Breton et al (2012), patients who are to be managed with CISC for voiding dysfunction require a structured educational approach, which is focused on comprehension, performance, follow-up and adaptation. Patient education on how to effectively and successfully perform CISC is fundamental and contributes to positive outcomes, such as enhanced self-management, avoiding adverse effects in the case of infection and improved quality of life (Wilde et al, 2015). Catheter-associated urinary tract infection (CAUTI) is a concern often related to poor catheter insertion technique (Jones et al, 2019). Educating the patient as well as family members on correct catheter insertion, CAUTI prevention and catheter care remains the ultimate strategy for preventing CAUTI (Lee et al, 2015).

\section{Patient assessment and competency of CISC}

Determining the presence of residual urine using a portable 3D bladder scanner allows a non-invasive initial assessment before beginning CISC (Thanagumtorn, 2016). Symptom assessment is pivotal, and incomplete emptying, minimal voiding and straining to void are all indications of urinary retention (Kobayashi et al, 2019). A patient assessment of whether or not the individual can adequately perform CISC is essential. According to Robinson (2006), a thorough nursing assessment needs to be undertaken to ascertain if the patient is suitable for and capable of undertaking the procedure. Although CISC is the most safe and effective method for draining residual urine, it is often reported that patients do not carry out the technique as recommended, which raises questions of competency, understanding and whether the patient's environment is suitable for carrying out the task (Bolinger and Engberg, 2013). It is vital that patients have good dexterity to enable precise positioning and insertion of the catheter to effectively perform CISC (Robinson, 2006). Above all, through dialogue, nurses must evaluate patient satisfaction, attitude and persistence of carrying out CISC, as these factors are known to influence adherence (Barbosa et al, 2012; Hentzen et al, 2019).

\section{Patient support}

Performing CISC can be debilitating, and patient support is essential for providing reassurance. A study that explored the emotional responses of female patients learning to perform CISC identified that carrying out this intervention required a lifestyle adjustment and coping mechanisms, and engendered emotions of isolation with regard to seeking advice, lack of clarity and knowing whom to confide in (Ramm and Kane, 2011). Effective communication skills, as well as professional nursing attitudes, are instruments for promoting patient confidence when conducting CISC, and these result in better long-term compliance (Logan et al, 2008). Patient-centred care is fundamental, and ensuring patient choice with regard to catheter type and size influences adherence and enhances patient experience (Wilde et al, 2015). CISC can cause psychological distress for some patients and can be perceived as a burden by many (McClurg et al, 2018). Nonetheless, reinforcing the importance of patient-centred care for those who require CISC is pivotal, contributing to a positive perception of quality of life and enhanced self-dignity and self-esteem (Logan et al, 2008; Shaw and Logan, 2013).

\section{Conclusion}

Urinary retention is the inability to passively void urine, and CISC is recommend for alleviating the symptoms of this condition. Although it is a common clinical procedure, patient education and support are necessary to ensure compliance. Assessment of patient symptoms, competency and skill to perform 
the task is fundamental. Nurses have a key role to play in educating patients on how to self-catheterise, as well as in monitoring compliance and adherence to the task. Patient support is crucial, and nurses must reinforce the importance of promoting patient-centred care before and after the initiation of CISC.

Barbosa CD, Balp M-M, Kulich K, Germain N, Rofail D. A literature review to explore the link between treatment satisfaction and adherence, compliance, and persistence. Patient Prefer Adherence. 2012;6:39-48. https://doi. org/10.2147/PPA.S24752

Blok B, Pannek J, Castro-Diaz D et al. EAU guidelines on neuro-urology. 2017. https://tinyurl.com/yylmvya3 (accessed 26 July 2019)

Bolinger R, Engberg S. Barriers, complications, adherence, and self-reported quality of life for people using clean intermittent catheterization. J Wound Ostomy Continence Nurs. 2013;40(1):83-89. https://doi. org/10.1097/WON.0b013e3182750117

Dougherty L, Lister S,West-Oram A.The Royal Marsden manual of clinical nursing procedures. 9th edn. Student edn. Chichester:Wiley Blackwell; 2015

Hentzen C, Haddad R, Ismael SS et al. Predictive factors of adherence to urinary self-catheterization in older adults. Neurourol Urodyn. 2019;38(2):770-778. https://doi. org/10.1002/nau.23915

Jones LF, Meyrick J, Bath J, Dunham O, McNulty CAM. Effectiveness of behavioural interventions to reduce urinary tract infections and Escherichia coli bacteraemia for older adults across all care settings: a systematic review. J Hosp Infect. 2019;102(2):200-218. https://doi.org/10.1016/j.jhin.2018.10.013
Kobayashi M,Tokura Y,Kambara T, Nukui A, Kamai T. Feeling of incomplete emptying with little post-void residual in patients with lower urinary tract symptoms: clinical implications and treatment outcomes. Low Urin Tract Symptoms. 2019:11(2):O59-O64. https:// doi.org/10.1111/luts.12217

Le Breton F, Guinet A,Verollet A, Jousse M, Amarenco G.Therapeutic education and intermittent selfcatheterization: recommendations for an educational program and a literature review. Ann Phys Rehabil Med. 2012;55(3):201-212. https://doi.org/10.1016/j. rehab.2012.01.006

Lee KC, Chao YF, Wang YM, Lin PC. A nurse-family partnership intervention to increase the self-efficacy of family caregivers and reduce catheter-associated urinary tract infection in catheterized patients. Int J Nurs Pract. 2015;21(6):771-779. https://doi.org/10.1111/ ijn.12319

Liberman D, Milhouse O, Johnson-Mitchell M, Siegel SW. Real-world retention rates after intravesical onabotulinumtoxin A for idiopathic overactive bladder. Female Pelvic Med Reconstr Surg. 2018;24(6):404-407

Logan K, Shaw C,Webber I, Samuel S, Broome L. Patients' experiences of learning clean intermittent self-catheterization: a qualitative study. J Adv Nurs. 2008;62(1):32-40. https://doi.org/10.1111/j.13652648.2007.04536.x

McClurg D,Walker K, Pickard R et al. Participant experiences of clean intermittent self-catheterisation, urinary tract infections and antibiotic use on the ANTIC trial—a qualitative study. Int J Nurs Stud. 2018;81:1-7. https://doi.org/10.1016/j. ijnurstu.2018.01.012

Ramm D, Kane R.A qualitative study exploring the emotional responses of female patients learning to perform clean intermittent self-catheterisation. J
Clin Nurs. 2011;20(21-22):3152-3162. https://doi. org/10.1111/j.1365-2702.2011.03779.x

Robinson J. Intermittent self-catheterization: principles and practice. Br J Community Nurs. 2006;11(4):144 146, 148 passim. https://doi.org/10.12968/ bjcn.2006.11.4.20833

Shaw C, Logan K. Psychological coping with intermittent self-catheterisation (ISC) in people with spinal injury: a qualitative study. Int J Nurs Stud. 2013;50(10):13411350. https://doi.org/10.1016/j.ijnurstu.2013.01.009

Somers SA, Mahadevan R for the Center for Health Care Strategies, Inc. Health literacy implications of the Affordable Care Act. 2010. https://tinyurl.com/ y6p6vswp (accessed 26 July 2019)

Thanagumtorn K. Accuracy of post-void residual urine volume measurement using an ultrasound bladder scanner among postoperative radical hysterectomy patients. J Med Assoc Thai. 2016;99(10):1061-1066

Vahr S, Corbussen-Boekhorst H, Eikenboom J et al for the European Association of Urology Nurses. Evidence based guidelines for best practice in urological health care. 2012. https://tinyurl.com/yy7dealn (accessed 26 July 2019)

Vahr S, Corbussen-Boekhorst H, Eikenboom J et al for the European Association of Urology Nurses. Catheterisation urethral intermittent in adults. 2013a https://tinyurl.com/y5rlcn4t (accessed 26 July 2013)

Vahr S, Corbussen-Boekhorst H, Eikenboom J et al for the European Association of Urology Nurses. Dilatation urethral intermittent in adults. 2013b. https://tinyurl. com/y623kr4r (accessed 26 July 2019)

Wilde MH, Fairbanks E, Parshall R et al. A web-based self-management intervention for intermittent catheter users. Urol Nurs. 2015;35(3):127-138

Yen PH, Leasure AR. Use and effectiveness of the teachback method in patient education and health outcomes. Fed Pract. 2019; 36(6):284-289 